\title{
Cricket bats, \#riotcleanup and rhubarb: everyday creativity in Twitter interactions around Test Match Special
}

\author{
Julia Gillen
}

\begin{abstract}
Changes in society brought about by use of social media have reverberated in public sports discourse giving opportunities for performances of shared culture. I investigate everyday linguistic creativity in the communicative practices of Jonathan Agnew, a commentator for the British Broadcasting Corporation and his networked audiences through Twitter and the radio programme, Test Match Special (TMS).

I explore how Agnew and others demonstrated linguistic creativity in situated interactions, transversing physical/digital boundaries that were entwined with specific socio-economic and historical contexts. Through the analysis of two topic clusters, I show how collaboratively constructed shared cultural understandings of the setting and flows across two media channels invoke complex chronotopes. Twitter performances of layered simultaneity are shown to be valued elements of creativity. This study contributes to current sociolinguistic research in expanding understandings of (i) everyday linguistic creativity as strategic performance in specific, complex contexts; (ii) how space and time can be discursively reworked in social media, sometimes presumed to be concerned with the present moment; and (iii) how flexible approaches to ethnography can contribute to such research.
\end{abstract}

Keywords:

cricket; linguistic creativity; social media; sports discourse; Twitter.

\section{Introduction}

In this paper I explore performances of everyday linguistic creativity and the evolution of relationships between professional commentary and audience, centred on English Test match cricket as discussed on a British Broadcasting Corporation (BBC) radio programme and Twitter. The field of public sports media is one among many in which opportunities for interactions between professional commentators and audiences are being reconfigured (Boyle and Haynes, 2013). New spaces are being opened up for the performance of everyday creativity in displays of knowledge, wit and humour, including in interactions between professionals and their publics, hitherto largely separated. 
Professional discourse is conventionally characterised by being located in specific situations, demarcated by time and space, and through identifiable goals (Gunnarsson, 2009). In sports commentary a goal is to make, and maintain over time, a space in which audiences can share the sense of being part of a community of aficionados (Schirato, 2013). For many decades in the twentieth century, professionals had relatively uncontested arenas in which to be authoritative, commanding the airwaves through their oral comments whether or not combined with visual elements, or through print and images in newspapers and specialist publications. Yet, nevertheless, a significant element of their activity was focussed not solely on competent and entertaining reporting, but also encouraging audience members to feel involved (Booth, 2008). They did offer spaces for members of audiences to interact with them but these were carefully regulated and demarcated in space and time, for example through letter columns and radio phone-ins. As digital communications began to permeate society, new channels such as email allowed ways for sports fans to have their say, although still in formats controlled by media professionals.

In recent years however social media platforms such as Twitter have engendered new ways for audience members to participate in public dialogues about sport. Such conversations do not only connect audience members to each other, potentially creating their own audiences in turn, but also facilitate dialogues with professional commentators, and even players. The sports media landscape is thus transformed, and has become a central element in many people's lives and their sense of identity (Boyle and Haynes, 2009). Much research has identified the opportunities created by social media to elicit or extend everyday performances into more public highly dialogic zones of interaction (Barton and Lee, 2013; Marwick and boyd, 2010; Page, 2012). As Papacharissi, (2012, p. 1990) declares, 'online social platforms collapse or converge public and private performances, creating both opportunities and challenges for pursuing publicity, privacy and sociality.' Papacharissi (2012) here draws on Goffman's (1959)'s broadening of the notion of performance from theatrical and related spheres to everyday life. Goffman (1959, p. 15) defines performance as 'all the activity of a given participant on a given occasion which serves to influence in any way any of the other participants.' Such a focus on audience aligns with an understanding of language as dialogic, always situated not only in material characteristics of space and time, but as also dependent on participants' understandings (Volosinov, 1995).

This dialogicality in chains of communication is historically contingent and contains possibilities for interactions that may be intended and perceived as creative. Discussions of creativity in language have extended their reach into the everyday (Carter, 2004; Cook, 2000; Swann, 2006), while preserving a sense of artistry, of individual intent, that is also captured in the notion of performance. Furthermore, 
everyday linguistic creativity, the focus of the special issue to which this paper contributes, is always situated and needs to be examined 'in the dialectic between performance and its wider socio-economic context' (Bauman and Briggs, 1990, p. 61)

Sports media operate across channels and modes, with complex temporal, spatial and material/virtual dimensions of dialogues. Commentaries may draw on specificities of their physical and socio-political environments. Anchimbe (2008) discusses the use of terms such as "a banana shot" in football commentary in Cameroon and "a ground-to-ground missile" on the West Bank. He discusses too the effects of the affordances of the medium used, contrasting radio, television and loudspeaker commentaries. An important aspect of the medium is the extent to which it allows audience participation and how that is structured. Although Bauman and Briggs, (1990, p. 63) were writing before the advent of the internet into society at large, let alone SMS, they noted that 'participation structure, particularly the nature of turn-taking and performer-audience interaction, can have profound implications for shaping social relations.' Professionals and fans shape their communications in accordance with the participation structure afforded to them by the channels they choose to interact with, their own purposes and understandings of cultural practices.

Everyday linguistic creativity emerges then from local understandings of the materiality of the channels, the cultural practices embodied by individuals and a dialogic attunement to other participants in the interaction (Maybin and Swann, 2007). As shall be discussed further below, an ethnographic stance is desirable to approach the complexities involved in investigating the communicative practices and viewpoints by participants who are tracked across various fields of their activities (Androutsopoulos, 2008; Hine, 2000; Pink et al., 2016).

\section{Test Match Special, cricket and opportunities for linguistic creativity}

There are three linked factors involved in shaping this setting for investigation of everyday performance, taking this as always contextualised in dynamic fashion, that is shaping and shaped in negotiations by participants in social interaction (Bauman and Briggs, 1990, p. 68). First, there is the nature of Test Match cricket itself and its relationship with the BBC. Second, Test Match Special (TMS), the BBC's radio programme, is embedded in a culture of multiple chronotopes, in which links are discursively constructed and frequently remade between moments, years and even decades. Third, innovations in social media have created new opportunities for prominent people to engage in 'celebrity as an organic and ever-changing performative practice..... [t]his involves ongoing maintenance of a fan base, performed intimacy, authenticity and access, and construction of a consumable persona' (Marwick and boyd, 2011, p. 140; emphasis as original). These are new spaces for dialogue with their audiences, and for those members of the audience to 
communicate with each other in networked audiences, including through creative performances. I will further elucidate these three factors or characteristics, before turning to the background of my project and the aims and methods of this paper in particular.

The first characteristic then of the cultural practice studied here, the networked audience around Jonathan Agnew, a BBC commentator, and Test cricket, is the socio-economic nature of the sport. Cricket is geographically constrained to certain countries of the world, especially members of the Commonwealth since it originated in Britain and was spread through colonialism. The game of cricket takes place in various formats: Test cricket, discussed here, is played over a maximum of five days between two international teams ${ }^{1}$. In England its long traditions and associations with the establishment mean that, in common with other major sports, it had by the end of the twentieth century become a 'recognizable and relatively autonomous cultural field' (Schirato, 2013, p. 14). In 2006, the House of Commons Culture, Media and Sport Committee set out its intent that the sport they described as 'squarely at the forefront of the nation's sporting affection' should be shown on a free to air TV channel. However, the international economic and political power of Sky TV proved stronger and so at the time of this study the BBC, the national public service broadcaster, was prevented from televising the game, the most obvious and lucrative way of bringing a sport to its distanced audiences. The consequence, that that the BBC was restricted to radio coverage, doubtless contributed to a perception of Test cricket in many quarters as relatively old-fashioned, tending to appeal to an older demographic.

TMS is at the centre of the BBC coverage. It has broadcast 'ball-by-ball' i.e. continuous commentary, since 1957, with a relatively short chain of central commentators. Supplemented by so-called summarisers, providers of additional comments, a great deal of continuity in practice is provided. In 2011, the journalist David Thomson, then based in San Francisco, wrote in a blog for The Economist of his amazement that the programme although now available online was essentially unchanged since the 1950s (Thomson, 2011). His illustration, a photograph of TMS commentator Henry Blofeld and summariser Geoffrey Boycott each in somewhat anachronistic clothing, acted as a discursive-semiotic artefact emphasising this sense of tradition.

\footnotetext{
${ }^{1}$ Discussions of cricket in this paper should be understood as applying to international Test cricket played by men and not other formats or participants. These differ in virtually all dimensions including media interactions around them. As Watson (2011) notes, part of the distinctive character of Test cricket lies in 'othering' other forms, but this is not part of my purview here.
} 
The second characteristic of the context for this study is how it is discursively constructed with particular reference to timescales. Bakhtin's (1981) idea of chronotopes as developed by Lemke (2005) is particularly useful here. This avoids metaphors of linearity or concentric circles for time-based relationships, but rather emphasises how 'meaningful activities are linked across timescales by our use of discursive-semiotic artifacts' (Lemke 2005, p. 110). Similarly, Blommaert (2005) discusses the relationship of intertextuality with multiple timescales, writing of utterances or written texts:

...we have to conceive of discourse as subject to layered simultaneity. It occurs in a real-time, synchronic event, but it is simultaneously encapsulated in several layers of historicity, some of which are within the grasp of the participants while others remain invisible but are nevertheless present. (Blommaert, 2005, p. 130; emphasis as original)

Linked with a sense of continuity with the past in the programme's longevity is the variety of multiple timescales or chronotopes present in its content. A key underlying basis for this lies in the duration of the game and its accompanying commentary. Owing to the physical constraints of the human frame, the length of up to five consecutive days for a single game necessitates many breaks from play at various scales, including, at the relatively long scale meal breaks and at the shortest scales moments while the ball is brought back into play. There are various other rule-governed intervals as well. Therefore radio commentators have to fill a great deal of time talking about other activities than action of that moment in play. They strive to broaden out listeners' understandings of events, including through descriptions of what can be seen and heard in and around the game, such as the spectators' behaviours, the ground, any visiting wildlife, the weather and so on. They also enhance understanding of the sportsmen's activities through frequent discussions of 'historic records and statistics ... part of the construction of Test cricket as a serious business' (Watson, 2011, p. 1385). These are often made more vivid through references to personal memories, since cricket experiences of commentators can be summoned over decades, through their participation in various capacities, such as having played themselves forty years earlier.

The central communicative practices of TMS are, as would then be expected, those of radio broadcast to an unseen audience. Its distinctive format while play is in progress is to draw on a roster of pairs who work for around 20 minutes at a time. The pair consists of a commentator, tasked with describing all the action, accompanied by a summariser. These two are occasionally supplemented by a third person, an onhand statistician/historian (called, with British understatement, the 'scorer'). As Tolson (2006, p. 106) explains, drawing on Bakhtin's (1986) notion of speech genres, in contemporary cricket commentary these two or three people 'talk to each other as much as they address listeners directly.' These dialogues also 
feature other interactions, carefully supported by the production team such as phone-ins during a long break. Email is another established means of connecting with the audience, with selection, revoicing and responses subject to editorial control.

Greater interactivity in sports discourse 'functions as both a lure and a way of transforming a viewer's relation to a game' (Schirato, 2013, p. 127). There are then spaces in sports discourses such as cricket commentary offered for everyday performance of linguistic creativity. Being able to perform with verbal artistry in ways that are received as topical and witty may well be the currency that gets an email selected through editorial moderation, and thus through recontextualization contributes to the ongoing discourse experienced by others. Phone-ins are a little less controllable at the point of utterance but an audience member usually has to undertake some rehearsal with a production member prior to being aired, and, of course, can be cut off, or indeed extended, if their performance is valued.

However, on distinctly separate platforms such as Twitter editorial control slips away from the broadcasters and an uncontrollable networked audience emerges. As Marwick and boyd, (2010, p. 129) explain: 'In contrast to the imagined broadcast audience, which consumes institutionally-created content with limited possibilities for feedback, the networked audience has a clear way to communicate with the speaker through the network.' Any member of the networked audience can contribute to a discussion, although they cannot, as shall be seen, determine how widely their participation will reach. Strategic ways of joining a discussion on Twitter include addressing somebody by means of the '@' symbol, or contributing to a thread by deploying a salient '\#' hashtag.

\section{Methodology}

My ethnographic approach aims at studying communications in their dynamic contexts, recognising these are fluid and vary from specific viewpoints. I have been looking at connections between uses of diverse media and the performance of identities online including through the public construction and maintenance of relationships. The original stimulus for this project lay in an exploratory study of Twitter over a year in a dual auto-ethnography (Author 2011). Through this I had identified cricket media as a site of creativity in writing not just among professionals, as has been recognised for over a century (Lee, 1997), but increasingly among members of their audiences on various digital platforms. Internet fora, Twitter and many other channels have been enthusiastically populated by fans eager to show off their knowledge and to argue with experts, often displaying sophisticated consciousness of the characteristics and conventions of the specific platforms, often aware of humour and wit as prized currency. With some similarities, Kytölä, (2013) 
has demonstrated in detail how a shared sense of culture infused the Finnish football forums he studied. I became interested in how audiences were becoming participants in new kinds of dialogic performances around Test cricket.

Recognising the need to investigate 'ethnographic and analytical form-functionmeaning interrelationships within situational contexts of language use' (Bauman and Briggs, 1990. p. 79), I began an ethnographic study focused on the journalist Jonathan Agnew. I had identified him as an "internet change agent" (Mullins et al., 2008), highly involved in social media, forums and other digital technologies, and an advocate for innovation in TMS. At the same time, as the BBC's chief cricket commentator he is also strongly identified by traditional audiences as 'combin[ing] astute journalism with apparently effortless communicative skills' (Steen, 2008, p. $61)$.

Hine (2000) proposes virtual ethnography as an 'adaptive ethnography which sets out to suit itself to the conditions in which it finds itself' (Hine 2000, p. 65).

Accordingly I combine 'person-centred ethnography' (Deumert 2014, p. 27) with 'social media ethnography' Postill and Pink (2012). Postill and Pink (2012, p. 127) advocate tracing 'digital socialities' (Postill and Pink, 2012, p. 127), i.e. the building of relationships not confined to a single platform. This boundary-crossing also permits the use of the oft-contested concept of 'community'- used as a way of interrogating what meanings these connections have for participants' sociality rather than in any ultimately problematic sense of an empirically bounded set. Such 'mobile methods' (Büscher, Urry, and Witchger, 2010) align with understandings of ethnography as reflexive, highly dependent on the paths the researcher selects. Such a methodology is always highly contextualised, perceiving the ethnographer's subjectivity as not just inevitable but also a potential strength in ascertaining the value of methods and remaining flexible.

My data collection for the person-centred social media ethnography took place from March 2010 until February 2013 and is summarised in Table 1 (See also Author 2014). For this paper I turn to the most intensive single day of data collection, working with a background of knowledge gained through the preceding 17 months.

\section{TABLE 1}

Table 1: Data collected

\begin{tabular}{|l|l|l|l|}
\hline Date & Media type & Details & $\begin{array}{l}\text { Methods of data collection } \\
\text { and selection }\end{array}$ \\
\hline 3 Mar 10 & $\begin{array}{l}\text { Interactive } \\
\text { website }\end{array}$ & $\begin{array}{l}\text { www.testmatchextra.com } \\
\text { synchronous chat } \\
\text { between Agnew and }\end{array}$ & $\begin{array}{l}\text { participation; screenshots; } \\
\text { fieldnotes; texts copied to } \\
\text { Word documents. }\end{array}$ \\
\hline
\end{tabular}




\begin{tabular}{|c|c|c|c|}
\hline $\begin{array}{l}20 \text { Jul } 11 \\
28 \text { Jul } 11 \\
9 \text { Aug } 11\end{array}$ & & $\begin{array}{l}\text { public (effectively } 30 \\
\text { minute q \& a) }\end{array}$ & \\
\hline $\begin{array}{l}\text { May - } \\
\text { December } \\
2010\end{array}$ & Twitter & $\begin{array}{l}\text { sample tweets from } 6 \\
\text { days }\end{array}$ & $\begin{array}{l}\text { occasional screenshots; } \\
\text { copying of some text to } \\
\text { Word documents. }\end{array}$ \\
\hline 2011 & Book & $\begin{array}{l}\text { Agnew, J. (2011) Aggers' } \\
\text { Ashes: the inside story of } \\
\text { England's } 2011 \text { Ashes } \\
\text { Triumph. London: Blue } \\
\text { Door (HarperCollins). }\end{array}$ & $\begin{array}{l}\text { All mentions of media } \\
\text { throughout sections of the } \\
\text { text written by Agnew. } \\
\text { (The book also contains } \\
\text { some writing by others, } \\
\text { reproduced from other } \\
\text { sources, which I excluded, } \\
\text { and quotations from Test } \\
\text { Match Special.) All these } \\
\text { were copied to an Access } \\
\text { database and then coded } \\
\text { according to } \\
\text { types/technologies of media } \\
\text { in the terms he employed. }\end{array}$ \\
\hline $\begin{array}{l}10 \\
\text { August } \\
2011\end{array}$ & $\begin{array}{l}\text { Twitter, } \\
\text { radio }\end{array}$ & $\begin{array}{l}\text { Collection of all tweets } \\
\text { by Agnew and some } \\
\text { related tweets; others; } \\
\text { TMS and } \\
\text { communications } \\
\text { technologies }\end{array}$ & $\begin{array}{l}\text { All tweets by Agnew } \\
\text { collected in real time, also } \\
\text { the most immediately } \\
\text { relevant tweets interacting } \\
\text { with his, including } \\
\text { anything replied to and } \\
\text { immediate responses. } \\
\text { Preserved by copying into } \\
\text { Word file; some sample } \\
\text { screen shots; sample related } \\
\text { tweets by other cricket } \\
\text { commentators; fieldnotes } \\
\text { through day on all } \\
\text { mentions of } \\
\text { communications } \\
\text { technologies }\end{array}$ \\
\hline 11 & Twitter, & 1 hour sample of Twitter & Notes; copying of texts of \\
\hline
\end{tabular}




\begin{tabular}{|c|c|c|c|}
\hline $\begin{array}{l}\text { August } \\
2011\end{array}$ & radio & and radio & $\begin{array}{l}\text { selected tweets; screenshot } \\
\text { (in order to ascertain if } \\
\text { there was any distinctive } \\
\text { difference from the } \\
\text { previous day). }\end{array}$ \\
\hline $\begin{array}{l}12 \\
\text { August } \\
2011\end{array}$ & $\begin{array}{l}\text { BBC sports } \\
\text { website }\end{array}$ & $\begin{array}{l}1 \text { day's live coverage, } \\
\text { compiled by Tom } \\
\text { Fordyce }\end{array}$ & $\begin{array}{l}\text { Collection of all } 213 \\
\text { postings copied to Word. } \\
\text { Sources of contributions by } \\
\text { channel and role of } \\
\text { contributor categorised } \\
\text { through spreadsheet. }\end{array}$ \\
\hline $\begin{array}{l}1 \\
\text { December } \\
2011\end{array}$ & Twitter & Moussaka narrative & $\begin{array}{l}\text { A story co-constructed with } \\
\text { wife; captured through } \\
\text { screenshots }\end{array}$ \\
\hline $\begin{array}{l}26 \text { March } \\
2012\end{array}$ & $\begin{array}{l}\text { Photo site } \\
\text { linked to } \\
\text { from } \\
\text { Twitter, } \\
\text { Twitter, } \\
\text { radio }\end{array}$ & $\begin{array}{l}\text { Geoffrey Boycott and the } \\
\text { power cut narrative }\end{array}$ & $\begin{array}{l}\text { A story told in commentary } \\
\text { and through social media- } \\
\text { captured through notes, an } \\
\text { image by Agnew linked to } \\
\text { from Twitter and texts of } \\
\text { relevant tweets. }\end{array}$ \\
\hline $\begin{array}{l}5 \\
\text { December } \\
2012\end{array}$ & $\begin{array}{l}\text { Twitter and } \\
\text { radio } \\
\text { commentary }\end{array}$ & $\begin{array}{l}1 \text { day sample of Tweets } \\
\text { and radio output }\end{array}$ & $\begin{array}{l}\text { Collection of all Agnews' } \\
\text { tweets, listened to his } \\
\text { commentary over one day } \\
\text { and made notes on } \\
\text { mentions of new media. }\end{array}$ \\
\hline $\begin{array}{l}\text { May } 2012 \\
- \text { January } \\
2013\end{array}$ & $\begin{array}{l}\text { online } \\
\text { newspaper } \\
\text { and cricket } \\
\text { forums }\end{array}$ & occasional examples & $\begin{array}{l}\text { purposive sampling } \\
\text { undertaken to explore } \\
\text { subjects related to Agnew, } \\
\text { Twitter and the cricket } \\
\text { media ecology }\end{array}$ \\
\hline $\begin{array}{l}\text { August } \\
2010- \\
\text { December } \\
2013\end{array}$ & $\begin{array}{l}\text { twitter } \\
\text { interactions }\end{array}$ & occasional examples & $\begin{array}{l}\text { occasional sampling of } \\
\text { Agnew's Tweets and } \\
\text { related Tweets by others }\end{array}$ \\
\hline $\begin{array}{l}17^{\text {th }} \\
\text { February }\end{array}$ & $\begin{array}{l}\text { Radio } \\
\text { programme }\end{array}$ & $\begin{array}{l}\text { available for download } \\
\text { via bbc.co.uk (in UK) }\end{array}$ & $\begin{array}{l}\text { transcribed talk relating to } \\
\text { Twitter }\end{array}$ \\
\hline
\end{tabular}




\begin{tabular}{|l|l|l|l|}
\hline 2013 & $\begin{array}{l}\text { (Desert } \\
\text { Island Discs })\end{array}$ & & \\
& & \\
\hline
\end{tabular}

The original choice of $10^{\text {th }}$ August 2011, the first day of a Test cricket match, was selected for data collection for reasons of convenience, since I could free it from other commitments. An importance piece of general background to mention, although it was not mentioned on TMS, is that the previous evening some English cities, including London and Birmingham had been affected by a wave of riots. On $10^{\text {th }}$ August Agnew worked on TMS, which was broadcast from $10.45 \mathrm{am}$ to $6.30 \mathrm{pm}$. He tweeted between $7.15 \mathrm{am}$ and $8 \mathrm{pm}$. I collected all his tweets, tracing connections to other tweets and collecting some of these other tweets. That is, if he retweeted somebody else's tweet, I looked back at their original tweet and twitter identity; if he replied to a tweet, similarly I endeavoured to collect their original tweet with their twitter identity (name and profile image). While listening to TMS I wrote three kinds of notes. First, I sought to rapidly transcribe some broadcast utterances by Agnew where they concerned topics that were also mentioned on Twitter, and briefly summarise others. Second, I captured all mentions of other media, such as phones and email made by Agnew and the other commentators and summarizers. Third, I wrote notes on events and activities that seemed to be noteworthy as to inform my understanding of the specificities of TMS on that particular day, as well as its relatively usual practices.

A significant characteristic of the data collected on this day is that I worked with two channels, Twitter and radio. It could be argued that in itself this is one more channel than many analyses address, but in the context of an ethnographic investigation it is a characteristic of my ethnographic placemaking (Postill and Pink, 2012), that could also reasonably be termed a limitation. I did not later gain more perspectives from participants in other ways or check interpretations, except through a few later email discussions with Agnew after the period of data collection including a draft of this paper.

Ethical considerations are a live and evolving issue when researching online (Markham and Buchanan, 2012). It is possible to argue that all texts appearing in a public space online are as public as poster advertisements in the physical environment and it would be as unnecessary to seek consent for reproduction and analysis as it would be to try to track down and seek informed consent from those involved in the authoring of such public texts. This is the practice in Computer Science. But I take a different view, informed by the British Association for Applied Linguistics (BAAL 2016) research guidelines and believe it is worth taking into consideration that new media channels such as Twitter are relative innovations. People using Twitter may not fully realise that their tweets can be captured and 
analysed by anybody who accesses them. By the time this study took place celebrity Twitter users were, in my opinion as already a longstanding user, aware of that. But I thought it still possible that people might come to Twitter, present themselves under the guise of their real identity, i.e. actual name in the physical world, and yet imagine interactions might be ephemeral. Therefore I decided to anonymise tweets where I did not feel certain that the author was consciously projecting a specific celebrity Twitter identity.

\section{Findings and discussion}

'Digital practices always transverse boundaries between the physical and the virtual, and between technological systems and social systems' (Jones, Chik, and Hafner, 2015 , p. 3). This truth was manifested in a particularly vivid fashion, as in a tweet by Agnew which juxtaposed archaic radio discourse with its digital context:

@Aggerscricket: For those listening online, the boffins are working to improve the line quality.

"Boffins" is a term more associated with the mid-late twentieth century to evoke scientists or technicians and "the line quality" would be more suggestive of landline telephones than relating to digital technologies. Agnew thus conveys an apology for a sound quality problem through juxtaposing contrasting normativities and chronotopes.

Two of his Twitter followers responded in kind. The first, after about 73 seconds, was:

Tweeter A: @Aggerscricket can't listen looters stole my radio \#LondonRiots [omitted twitter handle] \#afl360

Similarly to Agnew, Tweeter A crafts a performance around an analogue/digital absurdity. Clearly s/he (using a gender neutral handle) does have the potential capacity to listen, since TMS is broadcast online, but there is a play here with the reported tales of rioters or others following them using the public state of confusion to steal. Tweeter A also works to extend the possible audience of the humorous, addressing not just Agnew, but another Twitter user and finally an Australian talk show about football through "\#afl360. Within about 20 seconds, another respondent also plays interdiscursively with the crossover theme of Agnew's apology:

Tweeter B: @Aggerscricket Blowers is coming through loud and clear online here 
"Blowers" is the nickname of Henry Blofeld, the elderly and particularly traditional commentator referred to above. "Coming through loud and clear" again evokes radio in difficult conditions, such as ship-to-shore of several decades ago. The explicit mention of "online" plus the very fact that these communications are taking place on Twitter undercut the connotations of old technologies and, as Tweeter A's text discussed above constitute a performance of layered simultaneity.

Further findings are organised in two main topic-related clusters, demonstrating some of the diversity and range of ways people interacted with Agnew on Twitter. In these selections I have aimed to analyse everyday creativity, the fluid trajectories across media of interdiscursive texts and the contribution of Agnew as initiator, responder and relatively powerful mediator.

\section{Heralding the match: weather and \#riotcleanup}

One of the frequent themes before a day's cricket is begun is whether the match will go ahead. If the weather is too wet or stormy, play can be postponed or called off for the day. Therefore, one frequent pre-match concern of broadcasters and audience alike is the weather. On this particular morning it became apparent that there was another possible threat to the match being played, a concern for the safety of people in the aftermath of the riots; this was expressed in various ways. However, to begin with the weather: Agnew frequently takes to Twitter to discuss the topic hours before the start time. At 7.18 am his tweet was deftly concise:

@aggerscricket: @LucyWeather Edgbaston? Bit brighter?'

This is a good example of what Deumert and Lexander (2013), drawing from their research on SMS (texting), term textual linguistic dexterity: it is fast, brief and indexes both global and local forms. Although a short tweet, it is apparent from the name of the person addressed and the enquiry 'bit brighter?' that it concerns a weather forecast. Also interesting is the word 'Edgbaston'. Agnew has not selected a word that refers to the region: 'The Midlands' nor the county name, 'Warwickshire' nor indeed the salient city: 'Birmingham'. Rather, in choosing 'Edgbaston, ' he is highlighting the name of the cricket ground itself, implying that the person addressed, as well as of course the cricket community reading the tweet, would understand this reference.

The explicit addressee, @LucyWeather, is Lucy Verasamy, a metereologist employed by Sky TV. In itself this is interesting in that Sky, is the BBC's opposition, one might say victor, in the war over broadcasting cricket in England, and as such is never explicitly mentioned on TMS. The very brevity of Agnew's tweet suggests that he is confident of eliciting a response from this celebrity tweeter, as unless their 
professional relationship is cordial he would risk being ignored. Her immediately previous tweet had been:

@LucyWeather: rain in Manchester/Livepool today could hamper the clean up effort. brollies and well as brooms needed, @Riotcleanup

This tweet oriented to the wave of riots in many English urban centres. Over 130 arrests for rioting and looting in Birmingham alone had been reported the previous night ${ }^{2}$. Verasamy's posting, including 'clean up' and '@Riotcleanup' oriented towards what was being presented as a positive media story about the riots: the spontaneous actions of people who were voluntarily going into trashed streets with their own amateur housework tools to participate in a post-riot clean up. Twitter was the platform on which this collective action was mobilized, including citizen-led initiatives and mobilizations by local authorities; the Twitter account '@Riotcleanup' was a manifestation of this as well as the hashtag \#riotcleanup (Panagiotopoulos, Bigdeli, and Sams, 2014).

In her response to Agnew, which did not allude to the riots or the clean up, Verasamy responded appositely to weather concerns:

@LucyWeather: @aggerscricket quite a bit of cloud around with some patchy/light rain possible - most likely this morning.

This was much retweeted by followers of Agnew.

The topic of the weather was maintained, as a low-key if always prevalent topic thread on the radio and indeed Twitter, being always of relevance to cricket, not just affecting whether it is played or not but always available as a discursive resource since conditions, whatever they are, may be perceived as favouring one side over the other. The topic of the riots, and riot clean ups, on the other hand was unusual. Again, before the match, Agnew had much earlier dealt with this other potential threat to the match taking place by tweeting:

@Aggerscricket: For anyone concerned, I have spoken to ECB. Edgbaston Test goes ahead as planned.

Unlike @LucyWeather, @Aggerscricket is here omitting any indication of the nature of the actual threat. Moreover, he is demonstrating authority in expertise, in that not anybody can speak to the England Cricket Board and convey this air of official reassurance.

\footnotetext{
${ }^{2}$ www.bbc.co.uk/news/uk-england-birmingham-14452468 (accessed 24 February 2016).
} 
In response to this statement, comments from non-celebrities appeared on Twitter, directed at Agnew. The following sample of tweets beginning @Aggerscricket is arranged in chronological order.

Tweeter C: @Aggerscricket I'm worried about where I'll be staying though! May have to cancel the city centre premier inn!

Tweeter D: @Aggerscricket they may smash our cars, burn our shops, break our windows, they may take our football but they will never take our CRICKET!!

Tweeter E: @Aggerscricket is dhoni obliged to speak to broadcasters at toss? Can/ would he also refuse to speak to Sky?

Tweeter F: @Aggerscricket Just be bloody careful!!

Tweeter G: @Aggerscricket woohoo! brilliant news!

Tweeter H: @Aggerscricket looking for fun frivolity and fine cricket from aggers and co today. We all need cheering up from recent events

Tweeter I: @Aggerscricket Great news Aggers, let's hope that the rioters watch and learn some of the correct ways to behave.

Tweeter J: @Aggerscricket is the ground still there dumb cunts havnt burnt it Down and stole the sight screens have they

This cluster of tweets demonstrates a diversity of responses and, arguably, bears out the belief of Twitter's then CEO that, 'brevity results in creativity and wit' (Costolo, quoted by Choudhury, 2015). All posts demonstrate interesting features with some commonalities and differences in the performance of linguistic creativity. Tweeter D and Tweeter $\mathrm{H}$ both appear to pay considerable attention in crafting their productions. Tweeter $\mathrm{D}$ adopts a celebratory tone of resistance, parodying a speech from the popular film Braveheart, animated by William Wallace: 'They may take our lives but they will never take our freedom!' Tweeter $\mathrm{H}$ uses alliteration in another comparatively long tweet, keying his performance through 'fleeting uses of poetic language within everyday interactions' (Maybin and Swann, 2007, p. 502). Tweeters F and $G$ playfully evoke elements of orality, the first through a repetition of the exclamation mark that is conventionally understood to parallel strategies of oral emphasis; and the second through an exclamation that if performed orally would lead itself to an expression of excitement in its repeated vowel and intonation (Crystal, 2001; Darics, 2013). Tweeter I inserts himself ${ }^{3}$ in both an anti riot and a pro cricket discourse. His suggestion that the rioters might watch cricket and 'learn some of the correct ways to behave' is a flight of fancy, while associated with a conventional history of cricket: 'Just as Englishness expresses an illusion, so cricket is synonymous with a code of fine conduct which echoes times past or, more

\footnotetext{
${ }^{3}$ Where I use a pronoun of an anonymised Tweeter, it is to refer to the self-presentation of the user's Twitter identity while not making an absolute claim as to their actual identity.
} 
realistically, perceptions of long-gone ethics' (Lee, 1997, p. xi). Tweeter J's text, when recontextualised to appear in this thread, appears disruptive to the social order, expressing subversion and divergence from the norms of the others in its use of such non-standard features as swearing, unusual capitalisation and omission of punctuation. At the same time, however, the tweet aligns itself with those who condemned the rioters and supported \#riotcleanup. The notion of disruption works only in the context of my twitter feed, which is one of many ways in which this tweet could have been read. In another stream of tweets, somebody else's perspective, the linguistic features that appear divergent here could be less so. I observed that many tweets directed at Agnew did involve similar styles and although many of them involve negative responses to his messages some as this one do not. Further, the use of these features is not untypical of Twitter discourse (Papacharissi, 2012).

In terms of diversity of topic focus in reaction to the original tweet, Tweeter $\mathrm{E}$ and Tweeter C display a contrast. Tweeter E asks a question about the intentions of the Indian captain regarding pre-match interviews and the televising company, to which Agnew as an expert might reasonably be expected to have knowledge or express an opinion. Indeed a quarter of an hour before the beginning of the match Agnew did mention this situation in his radio commentary. On the other hand Tweeter $\mathrm{C}$, although addressing Agnew, is using Twitter to perform his 'networked self' communicating details of everyday life, possibly to invite advice from anybody appropriately informed (Papacharissi, 2012).

A further dimension of diversity is the variety of timescales alluded to here. I categorise the main time frames referred to as follows:

$\begin{array}{ll}\text { Tweet C } & \text { Future } \\ \text { Tweet D } & \text { Timeless } \\ \text { Tweet E } & \text { Future } \\ \text { Tweet F } & \text { Present } \\ \text { Tweet G } & \text { Present } \\ \text { Tweet H } & \text { Present } \\ \text { Tweet I } & \text { Future } \\ \text { Tweet J } & \text { Past }\end{array}$

This relative expansiveness of time reference counters the emphasis on 'foregrounding the present moment' in social media often assumed and discussed by Page, (2012, p. 191). This is an indication of the layered simultaneity (Blommaert 2005) or complexity of chronotopes (Lemke 2005) here coexisting in the TMS/Twitter networked audience. This finding is further developed in an examination of the second topic theme.

\section{Geoffrey Boycott's famous six}


At 14.35 in a break of play Agnew was talking on TMS with Geoffrey Boycott, a summariser and also former English player of a much earlier vintage. This gives him the licence to wander at will through Test cricket history, making connections with the game in the present moment. In the course of this dialogue Boycott claimed he had once hit a six at this ground. This is the highest scoring shot by a batsman, meaning he has hit the ball directly out of the field. Agnew, Boycott and experienced members of the radio audience would share the understanding that although Boycott had been one of England's highest scoring batsmen in history, he tended to reach high scores through accumulation of low-scoring shots rather than dramatic sixes. As Watson (2011) explains, a feature of TMS is a taking for granted of the audience's knowledge and understanding of both the history of the game and its technicalities. Even if these assumptions are in any specific instance incorrect, the effect is to invoke a sense of community infused by nostalgia in a performance of layered simultaneity (Blommaert 2005, p. 130).

In this instance Agnew proceeds to tease Boycott on the radio by pretending to doubt him, and, taking the opportunity to involve the audience, said, "If you were here, tms@bbc.co.uk.' Through providing the email address, without specifying the channel, Agnew draws on established understandings as to how to participate appropriately. Boycott interrupts him and pretends to be angry, keying a play frame through his exaggerated words and amused tone. Boycott threatens to contact Angnew's wife, presumably to complain of her spouse, an obviously incongruous and thus comic move. The two then return to commenting on the present cricket action.

However Boycott's claim of a famous six, now described as having happened in 1971 , is returned to as a topic of conversation at 14.39. Agnew says on the radio, 'Stephen $\mathrm{W}^{* * *}$ at Ashburton: definitely a top edge I remember it well'. The use of name plus place is a common device denoting a member of the public, as opposed to a summariser or other expert, and the omission of named communication channel implies a received email. The aspect of $\mathrm{W}^{* * * \prime} \mathrm{s}$ comment that makes this humorous to cricket fans is that the apparent support of Boycott's claim in 'I remember it well' is undermined by the suggestion of a 'top edge'. In cricket this is used of an accidental shot, thus suggesting that far from being a skilful accomplishment, the batsman made an error which luckily turned out well. The email thus subtly attacks Boycott's claim to prowess rather than substantiates it. Boycott immediately makes it evident he is central to the discourse community that delights in this clever use of specialist vocabulary, through again evincing more playful, exaggerated anger: 'How dare you say that?' So the collaborative joking continues.

At 14.54, when the radio talk about the claimed six had subsided, Agnew retweets the following: 
@Aggerscricket: RT@Tweeter L: Agnew! I was there when Boycs hit 6! Wasn't he using 1 of his patent rhubarb bats too? Almost made Warwks crumble!

It was impossible using my methods to investigate how fast and wide this tweet spread, but it was immediately evident to me at the time as a particularly witty use of language within the constraints of Twitter. It refers intertextually to a frequent humorous trope of Boycott, comparing a cricket bat to a stick of rhubarb. He frequently does this when arguing that the batsman's current task should be easy, thus criticising them in implied contrast to his own former skillset. Another connotation of rhubarb, this time not specific to Boycott, is that of a traditional English dessert dish known as rhubarb crumble. Here Tweeter L is punning with a double meaning of 'crumble', both the dessert and a term used to describe a sporting team collapse towards a position of defeat. Tweeter $\mathrm{L}$ is thus cramming interwoven humorous references into one short tweet, succeeding in referring interdiscursively to the previous humorous exchanges on the radio. He also conveys expertise in cricket discourses including through using appropriate means of compressing Boycott's and a team's names, abbreviating them to fit the constraints of a tweet. Again, this invokes the discourse community around cricket in that 'Warwks' can be recognised as standing for Warwickshire, a county cricket team, based at Edgbaston. Again the use of specialised vocabulary is deployed as a resource for creativity. Since the famous 6 joke had already been persisted with for some time, its reemergence this much later does not prevent appreciation; the asynchronous material quality of the Twitter interactions do not harm the humorous effect that would probably require rapidity of turn-taking in face to face interaction (North, 2007, p. 546).

At 16.06 Christopher Martin-Jenkins, Agnew's older colleague, uses a short break in play to read out an email from the bowler against whom Boycott had scored the 6 referred to earlier. Boycott returns to his humorous confrontation with Agnew, calling, 'Where's Aggers? Where's Aggers?' as if to surprise him with confirmation of Boycott's point of view. The dialogue between Martin-Jenkins and Boycott, develops into comparisons with other past cricketers; this again is extended further by yet another commentator who draws on a conversation with another famous player about his experiences during the 1930s. This is all juxtaposed with ball-byball commentary and discussions of the current game and achievements of its players in multiple chronotopes. These entwined topic flows contribute to a sense of TMS contributing a narrative constructed as continuous in the sense that a novel narrates continuity over temporal interruptions, in which 'every Test is historically positioned and draws on this sense of continuity and tradition to signify its importance' (Watson, 2011, p. 1385).

Overall, my data in many ways echoed the findings of Kytölä and Westinen, (2015: 9) in their study of Finnish football forums which they found, "can provide a 
reference point for community construction and translocal identifications; they allow rhizomatic, translocal and transcultural traffic of cultural and multi-semiotic material with their associated identifications, styles, normativities and ideologies..."

The crossing between platforms is an important aspect of the construction of a sense of community. If one is only a radio listener, discussions are coherent and typical of TMS humour. If one is a participant in Twitter only, the extent to which specific tweets are understood is incalculable, given that each user shapes their own context differently. Yet tweets can still be appreciated. For a Test cricket fan, using both media simultaneously can lead to a fuller appreciation of the intertextuality between performances and unfolding narratives.

\section{Overview of the remainder of the day}

The day's cricket-related conversations included many themes developed by Agnew and interactants both on radio and Twitter, such as Agnew's diet. In details of topic and tone more diversity was displayed on Twitter. For example, the topic of the riots, although openly discussed on another BBC radio station during the match was backgrounded in TMS and never explicitly mentioned, although several oblique comments suggested to me that the commentators were chafing at a restriction. On Twitter, discussion was rife, becoming combative when it developed into a discussion of the reaction of the England cricket team to violence in the environment when touring India some years before. Some tweets directed at Agnew which were gloomy rather than angry in tone received encouraging replies, for example:

Tweeter M: @Aggerscricket Oh man. I don't want to know this any more. @Aggerscricket: @Tweeter M its not that bad!!

Tweeter N: @Aggerscricket I'm doing the rain dance! @Aggerscricket: @Tweeter N cheer up!

However, most tweets directed towards Agnew stressed a positive attitude, sometimes towards multiple aspects of the day. For example, alluding to \#riotcleanup:

Tweeter O: @Aggerscricket Not wishing to demean the other, worthy hashtag, but is it time for \#Indiacleanup?

Tweeter O is punning on "clean up" as used of a sporting victory as well as the more usual sense. Many such tweets demonstrate how the dispersed network of aficionados in the joint TMS radio audience and Twitter platform of Agnew's followers align themselves with an identity beyond simple cricket fandom. They 
perform as participants of this community, celebrating their shared culture and the values they associate with it. For example, just a minute after Tweeter O's post as discussed above:

Tweeter P: Cracking from England again! Bringing a modicum of cheer to another otherwise thoroughly depressing news day.

She is presumably invoking the topic of riots, as by the main news story, while echoing the TMS commentators in not referring to them explicitly. Towards the end of the day Agnew addressed his Twitter audience as a collective:

@Aggerscricket: Many nice comments here re TMS today. Thanks all. We simply aimed to put a smile on faces. Glad it helped.

Many responses to this addressed topics from earlier in the day that had crossed Twitter and radio commentary:

Tweeter Q: tops stuff today aggers, Blowers is still a legend. Hope the diet is not too restrictiv . Smile back on face

The references to Agnew, his fellow TMS commentator Blofeld and the topic of the diet that had transversed radio commentary and Twitter emphasise that it is the participation in the cross-platform community that is being viewed positively. It may be reading too much into Agnew's comment, 'We simply aimed to put a smile on faces,' that the unusually challenging situation of the nearby riots, dealt with on the radio by ignoring it, was referred to here. It certainly seems that whatever the cause of that sentiment, Tweeter $Q$ acknowledges and mirrors it in the parallelism of her final valediction, as if trying to write on behalf of the appreciative networked audiences.

\section{Conclusions}

This exploration has contributed to understandings of everyday creativity in exploiting the affordances of different channels and making connections across them. The professional journalist at the centre of my investigation, Agnew, expertly exploited the affordances of specific media channels and demonstrated his understanding of the differences between them. He could craft an effective tweet with three words of content to elicit a complex, knowledgeable response from a salient authority. His purpose in doing this was not just to gain knowledge for himself, but obtain it in such a way it was accessible to others. In this, as many other examples, he displayed understanding of how to shape a tweet as expertly as his radio commentary, although the latter had been honed over decades. He 
demonstrated also an understanding of the flows between media; where these could be permitted and where not. Thus, in deference to the shared expectations of which technologies the whole of his radio audience would have knowledge of and find acceptable, it was the older channels of radio itself, emails and phones that could be mentioned there. When Twitter was mentioned, once or twice, it was in an unthreatening way: he would not imply that a member of the audience might be missing out on something if they could not access Twitter.

Thomas (2014) suggests that in their performative identity management, 'practices around the presentation of the public self that were otherwise traditionally limited to the presentation of star personae are increasingly being mirrored by non-celebrity Tweeters.' This seems a plausible interpretation for how some of the artful tweeters quoted here, such as Tweeter D and Tweeter L might have become socialised into their skilful presentations. Yet, Agnew, as the celebrity commentator with command of the field, did much to orchestrate interactions around the match, making visible judgements as to the qualities of others' tweets and so demonstrating a relatively strong degree of power, countering the idea that Twitter is a wholly democratic or egalitarian space (Thomas, 2014). Through choosing which comments to respond to, celebrity Twitter users can choose to bestow the gift of amplifying the user's original utterance or text, beyond the original (potential) audience through replying, thus attracting some people's attention to the original tweet, or through retweeting, whether or not with an additional supplemental comment. Not least because of volume, most Tweets directly addressing Agnew would necessarily be ignored. Very occasionally a user might be castigated and visibly blocked. Thus, in comparison with traditional one-many broadcast audiences, issues of power and status remain discursively shaped, but may nonetheless contain significant asymmetries.

In this paper I have sought to contribute to the endeavour of this special issue in three ways. First I have explored how Agnew and his interactants creatively exploit the affordances of specific media channels, for varying effects, including the playful, and sometimes manage flows between them. Performances are shaped by the affordances of channels yet recontextualisations across channels can also be managed creatively, conveying 'polysemic content to audiences, actual and imagined' (Papacharissi 2012, p. 1989). Second I attended to how time is managed as a resource, and deployed in multiple ways, so that connections develop and deepen mutual understandings in the layered simultaneity of the present moment and linked chronotopes. Findings here have contributed to investigations as to how the supposed orientation of social media on the present moment can be challenged (Georgakopoulou, 2015; Georgalou, 2015). Taken together, these contributions demonstrate how a contemporary sociolinguistic investigation into language highlights strategic performance of creativity in everyday contexts. Rather than hived off into a separate realm of cyberspace, online interactions require a situated understanding including in terms of the sociocultural understandings of 
chronotopes that themselves invoke historicity at various levels. Third, I suggest that researching such interactions demand an adaptive mobility on the part of the researcher. I have demonstrated some of benefits and challenges of bringing an ethnographic approach to the study of a specific communicative practice. The researcher is as deeply implicated in the selection and following of virtual trails as they would be in the physical world.

\section{References}

Anchimbe, E.A., 2008. "Bend it like a banana:" representing the ecology in live football commentary, in: Lavric, E., Pisek, G., Skinner, A., Stadler, W. (Eds.), The Linguistics of Football. Gunter Narr, Tübingen, pp. 133-142.

Androutsopoulos, J., 2008. Potentials and limitations of discourse-centred online ethnography. Language@internet 5.

Bakhtin, M.M., 1986. Speech genres and other late essays. University of Texas Press, Austin, TX.

Bakhtin, M.M., 1981. The dialogic imagination. Four essays. University of Texas Press, Austin.

Barton, D., Lee, C., 2013. Language online: investigating digital texts and practices. Routledge, London and New York.

Bauman, R., Briggs, C., 1990. Poetics and Performance as Critical Perspectives on Language and Social Life. Annu. Rev. Anthropol. 19, 59-88.

Blommaert, J., 2005. Discourse. Cambridge University Press, Cambridge.

Booth, D., 2008. Talking of sport: the story of radio commentary. SportsBooks Limited, Cheltenham, Glos.

Boyle, R., Haynes, R., 2013. Sports journalism and social media: a new conversation?, in: Hutchins, B., Rowe, D. (Eds.), Digital Media Sport: Technology, Power and Culture in the Network Society. Routledge, New York, pp. 204-218.

Boyle, R., Haynes, R., 2009. Power play: sport, the media and popular culture.

Edinburgh University Press, Edinburgh.

British Association of Applied Linguistics, 2016. Recommendations on good practice in applied linguistics. http://www.baal.org.uk/goodpractice_full_2016.pdf accessed 26 February 2017.

Büscher, M., Urry, J., Witchger, K. (Eds.), 2010. Mobile methods. Routledge, Abingdon, UK.

Carter, R., 2004. Language and creativity: the art of common talk. Routledge, London.

Choudhury, A.R., 2015. Living in the moment: Twitter CEO Dick Costolo's decision to quit comes as a surprise but his belief in the platform remains. Bus. Times.

Cook, G., 2000. Language play, language learning. Oxford University Press, Oxford. Crystal, D., 2001. Language and the Internet. Cambridge University Press, 
Cambridge.

Darics, E., 2013. Non-verbal signalling in digital discourse: The case of letter repetition. Discourse, Context Media 2, 141-148. doi:10.1016/j.dcm.2013.07.002

Deumert, A., 2014. Sociolinguistics and mobile communication. Edinburgh University Press, Edinburgh.

Deumert, A., Lexander, K.V., 2013. Texting Africa: writing as performance. J. Socioling. 17, 522-546.

Georgakopoulou, A., 2015. Introduction: Communicating time and place on digital media-Multi-layered temporalities \& (Re)localizations. Discourse, Context Media 9, 1-4. doi:10.1016/j.dcm.2015.08.002

Georgalou, M., 2015. Beyond the Timeline: Constructing time and age identities on Facebook. Discourse, Context Media 9, 24-33. doi:10.1016/j.dcm.2015.07.001

Goffman, E., 1959. The presentation of self in everyday life. Doubleday, New York. Gunnarsson, B.-L., 2009. Professional discourse. Continuum, London.

Hine, C., 2000. Virtual ethnography. SAGE Publications, London.

Jones, R., Chik, A., Hafner, C.A., 2015. Introduction: discourse analysis and digital practices, in: Discourse and Digital Practices: Doing Discourse Analysis in the Digital Age. Routlledge, Abingdon, UK, pp. 1-17.

Kytölä, S., 2013. Multilingual language use and metapragmatic reflexivity in Finnish internet football forums : a study in the sociolinguistics of globalizationo Title. University of Jyväskylä, Jyväskylä.

Kytölä, S., Westinen, E., 2015. “I be da reel gansta” - A Finnish footballer's Twitter writing and metapragmatic evaluations of authenticity. Discourse, Context Media 8, 6-19. doi:10.1016/j.dcm.2015.05.001

Lee, C. (Ed.), 1997. Through the covers: an anthology of cricket writing. Oxford University Press, Oxford.

Lemke, J.L., 2005. Place, pace, and meaning: Multimedia chronotopes, in: Norris, S., Jones, R.H. (Eds.), Discourse in Action: Introducing Mediated Discourse Analysis. Routledge, Abingdon, UK, pp. 110-122.

Markham, A., Buchanan, E., 2012. Ethical decision-making and Internet research recommendations from the AoIR Ethics Working Committee (Version 2.0).

Marwick, A., Boyd, D., 2011. To See and Be Seen: Celebrity Practice on Twitter. Converg. Int. J. Res. into New Media Technol. 17, 139-158. doi:10.1177/1354856510394539

Marwick, A.E., Boyd, D., 2010. I tweet honestly, I tweet passionately: Twitter users, context collapse, and the imagined audience. New Media Soc. 13, 114-133. doi:10.1177/1461444810365313

Maybin, J., Swann, J., 2007. Everyday Creativity in Language: Textuality, Contextuality, and Critique. Appl. Linguist. 28, 497-517. doi:10.1093/applin/amm036

Mullins, M.E., Kozlowski, S.W.J., Schmitt, N., Howell, A.W., 2008. The role of the idea champion in innovation: The case of the Internet in the mid-1990s. Comput. Human Behav. 24, 451-467. doi:10.1016/j.chb.2007.02.001 
Neuliep, J.W., 2009. Intercultural communication: a contextual approach, 4th ed. SAGE Publications, Thousand Oaks, CA.

North, S., 2007. "The Voices, the Voices": Creativity in Online Conversation. Appl. Linguist. 28, 538-555. doi:10.1093/applin/amm042

Page, R., 2012. Stories and social media: identities and interaction. Routledge, London.

Panagiotopoulos, P., Bigdeli, A.Z., Sams, S., 2014. Citizen-government collaboration on social media: The case of Twitter in the 2011 riots in England. Gov. Inf. Q. 31, 349-357. doi:10.1016/j.giq.2013.10.014

Papacharissi, Z., 2012. Without you, I'm nothing: performances of the self on Twitter. Int. J. Commun. 6, 1989-2006.

Pink, S., Horst, H., Postill, J., Hjorth, L., Lewis, T., Tacchi, J., 2016. Digital ethnography: principles and practice. SAGE Publications, London.

Postill, J., Pink, S., 2012. Social media ethnography: the digital researcher in a messy web. Media Int. Aust. 145, 123-134.

Schirato, T., 2013. Sports discourse. Bloomsbury Academic, London.

Steen, R., 2008. Sports journalism: a multimedia primer. Routledge, London.

Swann, J., 2006. The art of the everyday, in: Maybin, J., Swann, J. (Eds.), The Art of English: Everyday Creativity. Palgrave Macmillan, Basingstoke, UK, pp. 3-28.

Thomas, S., 2014. Celebrity in the "Twitterverse": history, authenticity and the multiplicity of stardom Situating the "newness" of Twitter. Celebr. Stud. 5, 242255. doi:10.1080/19392397.2013.845962

Thomson, D., 2011. Test Match Special... in San Francisco [WWW Document]. Econ. blogs. URL http://www.economist.com/blogs/prospero/2011/08/cricket (accessed 2.26.17).

Tolson, A., 2006. Media talk: spoken discourse on TV and radio. Edinburgh University Press, Edinburgh.

Volosinov, V.N., 1995. Language, speech, and utterance, in: Dentith, S. (Ed.), Bakhtinian Thought: A Reader. Routledge, New York.

Watson, C., 2011. Test Match Special, Twenty20 and the future of cricket. Sport Soc. Cult. Commer. media, Polit. 14, 1383-1394. 